\title{
Dermatology Research
}

\section{A Simple, Versatile, Disposable, and Inexpensive Eye Patch}

\section{Jorge Schwember ${ }^{*}$, Gerardo Schwember ${ }^{2}$ and Luisa Madrid'}

${ }^{1}$ Centro Laser, La Serena, Chile.

${ }^{2}$ Clínica Alemana de Santiago. Hospital Padre Hurtado de Santiago, Chile.
*Correspondence:

Jorge Schwember, Centro Laser, Huanhuali 735, La Serena, 1720412, Chile.

Received: 01 November 2019; Accepted: 29 November 2019

Citation: Jorge Schwember, Gerardo Schwember, Luisa Madrid. A Simple, Versatile, Disposable, and Inexpensive Eye Patch. Dermatol Res. 2019; 1(2); 1-3.

An eye patch is usually used for occlusion therapy to prevent amblyopia [1] or as an eye pad dressing for neurotrophic keratopathy amid other therapeutical care [2], lagophthalmos [3], to protect the eye after an open trauma or after the removal of a foreign body embedded in the cornea, to avoid diplopia in temporary extraocular muscle palsy [4,5]. OpticludeR is one of the best known.

The authors have been using 1.5-inch width adhesive tape (MicroporeR) for the aforementioned purposes for many decades (Figure 1). In recent years they have been utilizing it to protect the eye during laser or intensive pulsed light (IPL) facial procedures. It must be noted that an additional metal shield is also essential (Figure 2). This eye patch has the following advantages compared to the traditional eye pad: it is cheaper, simpler, disposable, avoids the use of additional supplies and guarantees a total lid occlusion.

In laser or IPL procedures it eliminates the need to keep the eye shield in place and also avoids extra inventory items (Figure 3 ).
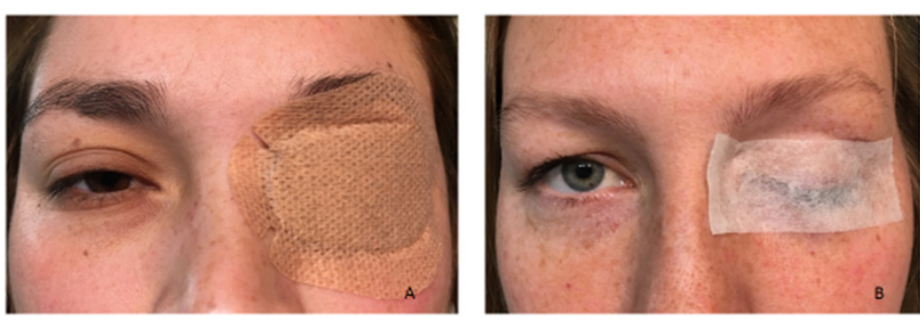

Figure 1: A- Standard eye pad dressing. B- The tape is applied directy to the eyelids with a narrow fold end at the nasal extreme facilitating its removal.

During our long experience, we have observed corneal erosions in some patients, especially in lagophthalmos, due to incorrectly applied eye pad dressings. The use of this tape guarantees complete eyelid closure. Patients are often concerned about loss of eyelashes upon removal of the tape, but this is not the case.

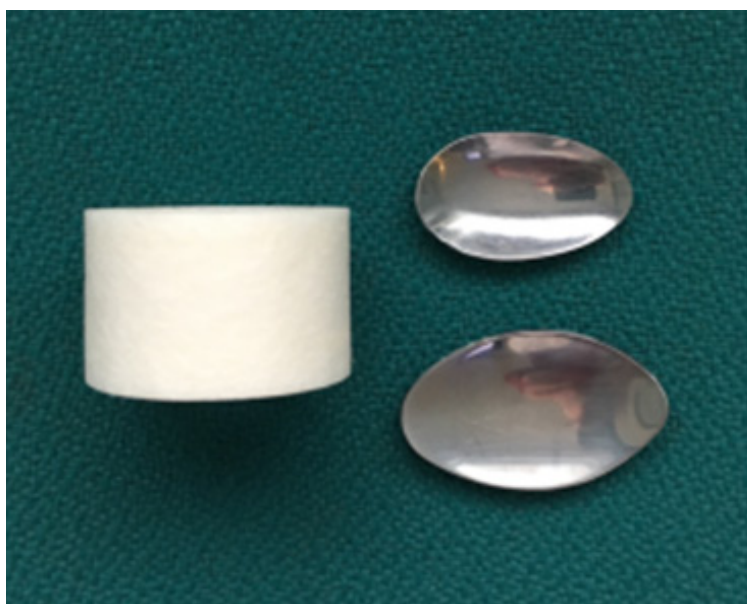

Figure 2: The two sizes of eye shields are obtained from metallic teaspoons.
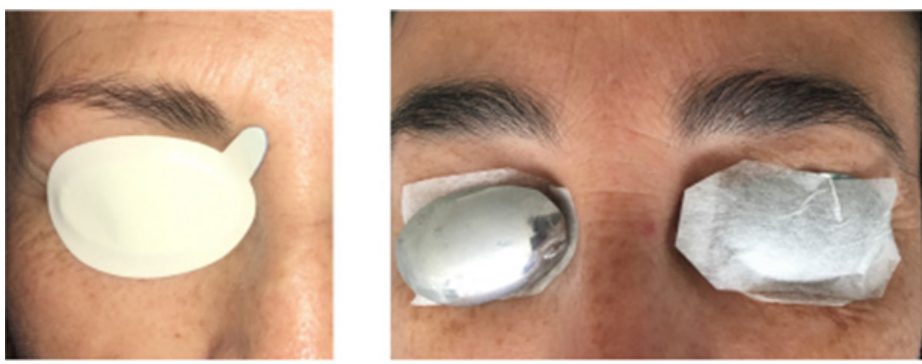

Figure 3: A- A commercial disposable eye shield that has a thin aluminum layer. B- Eye shields fixed with the tape during high light exposure procedures. The contour of the tape can be trimmed to an oval shape.

\section{References}

1. Georgievski Z, Koklanis K, Leone J. Orthoptists' management of amblyopia - a case based survey. Strabismus. 2007; 15: 197-203.

2. Sacchetti M, Lambiase A. Diagnosis and management of 
neurotrophic keratitis. Clin Ophthalmol. 2014; 8: 571-579.

3. Pereira MV, Glória AL. Lagophthalmos. Semin Ophthalmol. 2010; 25: 72-78.

4. Kernich CA. Diplopia. The Neurologist. 2006; 12: 229-230.
5. Asbury AK, Aldredge $\mathrm{H}$, Hershberg R, et al. Oculomotor palsy in diabetes mellitus: a clinicopathological study. Brain. 1970; 93: 555-566. 